\title{
A INFLUÊNCIA DO CONSTITUCIONALISMO PLURIUNIVERSAL E A NOVA ORDEM PROCESSUAL CIVIL BRASILEIRA
}

\author{
Adriana Aparecida Giosa Ligero ${ }^{1}$, Gilberto Notário Ligero ${ }^{2}$ \\ ${ }^{1}$ Universidade do Oeste Paulista, curso de Direito, Presidente Prudente, SP. ${ }^{2}$ Toledo Prudente Centro Universitário, \\ curso de Direito, Presidente Prudente, SP. E-mail: E-mail: giosaligero.adv@ig.com.br
}

\section{RESUMO}

Este artigo trata da influência do constitucionalismo moderno, multifacetário e em níveis sobre o direito processual civil, considerado um dos ramos mais importantes do direito público. A superação dos cânones convencionais exclusivistas do constitucionalismo tradicional, por força de uma sociedade aberta e pluralista, acabou por alterar as condições do processo civil, o qual passou a ser visto sob este prisma pluriuniversal, especialmente em tempos de um Novo Código de Processo Civil.

Palavras-chave: Constitucionalismo. Pluriuniversal. Processo Civil.

\section{THE INFLUENCE OF CONSTITUTIONALISM PLURIUNIVERSAL AND THE NEW CIVIL PROCEDURE ORDER BRAZILIAN}

\begin{abstract}
This article deals with the influence of modern constitutionalism, multifaceted and levels of the civil procedural law, considered one of the most important branches of public law. Overcoming the conventional exclusionary canons of traditional constitutionalism, by virtue of an open and pluralistic society, eventually alter the conditions of civil procedure, which was seen under this pluriuniversal light, especially in times of a new Civil Procedure Code.
\end{abstract}

Keywords: Constitutionalism. Pluriuniversal. Civil Lawsuit. 


\section{INTRODUÇÃO}

Atualmente, afirma-se que as ciências sociais, em todos os seus níveis, são construídas e se redimensionam não só em razão das necessidades humanas, mas principalmente por conta do dinamismo social.

Esta dinâmica social é marcada por um movimento globalizante, inclusivo, multifacetário e, ainda, fortemente influenciada por um caráter reflexivo, capaz de desfazer velhos paradigmas. Neste sentido, destaca-se que as convicções presentes no homem em um determinado momento da história são essenciais para entender o modo como vive e como enxerga o mundo.

Essas convicções decorrem do que José Ortega y Gasset (1982, p. 82) chama de crenças, ou seja, tudo aquilo que o homem acredita como capaz de mantê-lo vivo, o que torna viável e justificável sua existência.

Atualmente, o dinamismo social é guiado por uma cosmovisão sistêmica, porque o mundo não pode mais ser fruto de uma razão mecânica, como se tudo funcionasse em compartimentos estanques e fechados. Fritjof Capra (2002, p. 28) anuncia que outras teorias surgiram e merece destaque a teoria do pensamento sistêmico:

De acordo com a visão sistêmica, as propriedades essenciais de um organismo, ou sistema vivo, são propriedades do todo, que nenhuma das partes possui. Elas surgem das interações e das relações entre as partes. Essas propriedades são destruídas quando o sistema é dissecado, física ou teoricamente, em elementos isolados. Embora possamos discernir partes individuais em qualquer sistema, essas partes não são isoladas, e a natureza do todo é sempre diferente da mera soma de suas partes.

Esse pensamento é uma das grandes revoluções no pensamento científico atual, principalmente porque contraria o método reducionista cartesiano, posto que os sistemas não podem ser estudados em partículas, mas no todo, de maneira que, na abordagem sistêmica, as propriedades das partes somente são entendidas a partir da organização do todo.

A sociedade seria o resultado do sistema, de maneira que as relações entre os sujeitos que compõem essa sociedade se ramificam em redes e, de uma forma ou de outra, acabam influenciando a vida social como um todo.

Esse paradigma inclusivo foi citado, não por acaso, mas porque representa uma nova forma de pensar e ver o mundo atual. E, mais, ajuda a explicar a sociedade e as relações que ocorrem no seu âmbito.

Por força deste modelo sistêmico, pluriuniversal, inclusivo e colaborativo é que se objetiva com o presente artigo, estudar, ainda que brevemente, a influência do constitucionalismo na nova ordem processual civil brasileira, a qual está surgindo em razão de um novo Código de Processo Civil. 


\section{METODOLOGIA}

A metodologia utilizada na pesquisa foi eminentemente bibliográfica, tendo a intenção de possibilitar a compreensão do constitucionalismo multinível e sua influência no direito processual civil brasileiro. Além disso, valendo-se do raciocínio hipotético dedutivo, foram construídas as bases do trabalho, numa interpretação reflexiva e dialética.

\section{DISCUSSÃO}

A cosmovisão sistêmica, inclusiva e multifacetária acabou por influenciar a Ciência do Direito em vários sentidos, mas principalmente na construção de novos conceitos e interpretações.

Vários foram os ramos do Direito influenciados por este modo de ver o mundo, contudo, por ora e dentro dos limites deste ensaio, destacam-se o Direito Constitucional e o Direito Processual Civil.

No plano do constitucionalismo, verificou-se, em razão deste novo paradigma globalizante e pluralista, a superação do legalismo exclusivista constitucional. Este é o posicionamento doutrinário abalizado por Friedrich Müller (2010. p. 27), o qual defende a tese de que as metódicas jurídicas não representam um catálogo de técnicas de trabalho suficientes, conclusivas e inquestionáveis.

Mencionado autor acaba por esclarecer que: "a ênfase na objetividade pseudonaturalista dos "métodos" jurídicos empalidece juntamente com a força de convencimento do positivismo legal." (MÜLLER, 2010, p. 27).

De forma percuciente e esclarecedora, justificando uma reviravolta paradigmática, Friedrich Müller (2010, p. 28) traduz o que significa para ele a metódica do Direito Constitucional:

Como designação de uma concepção global sistematicamente reflexionante dos modos de trabalho do direito (constitucional), a "metódica" no sentido aqui usado é o conceito abrangente de "hermenêutica", "interpretação", "métodos de interpretação" e "metodologia". "Hermenêutica" não se refere aqui a tradicional doutrina da técnica retórica na sua aplicação à ciência jurídica, mas às condições de princípio da concretização jurídica normativamente vinculada do direito. "Metodologia" significa no sentido tradicional a totalidade das regras técnicas da interpretação no trato com normas jurídica, como e.g.a interpretação gramatical ou sistemático, o procedimento analógico e regras similares. [...] Por fim, "interpretação" ["Interpretation" ou "Auslegung"] diz respeito às possibilidades do tratamento jurídico-filológico do texto, i. e., da interpretação de textos e normas. Ocorre que uma norma jurídica é mais do que o seu texto de norma. A concretização prática da norma é mais do que a interpretação do texto.

A tese defendida pelo jurista e pensador alemão revela que o constitucionalismo não pode 
ser compreendido de forma estanque em um só nível. A compreensão contemporânea do Direito Constitucional exige do seu intérprete e aplicador uma visão ampla, ou seja, em vários níveis. Caíque Tomaz Leite da Silva (2014, p. 131), expressando seu posicionamento sobre tal fenômeno, o denomina de sincretismo constitucional, com o intuito de traduzir a ideia de que não se pode mais falar em universo constitucional, mas em pluriversum constitucional.

Em um estudo aprofundado sobre o tema da superação do paradigma da unicidade nivelar do Direito Constitucional e mencionando o exemplo vivenciado pela União Europeia e de modo especial a constitucionalização do direito público, do qual o Direito Processual Civil faz parte, o jovem internacionalista escreve:

A assunção do monopólio de realização judicativa do direito faz com que a Constituição Federal seja o instrumento normativo parâmetro de controle de legalidade das normas atinentes ao processo. Mas, mesmo limitando nosso conceito de constitucional ao direito público não posso restringir-me à Constituição pátria. O jusfundamental pode encontrar amparo jurídico normativo naquilo que se convencionou chamar de Constituição. Porque aquilo que o constitucional representa hoje já transbordou a muito as fronteiras do arquipélogo soberano segundo temos vindo a sustentar. (SILVA, 2014, p. 133)

Com esta lição doutrinária reforça-se o que vem se defendo até agora: o espaço do constitucionalismo atual deve ser estabelecido multiniveladamente.

Por fim e, em consonância com o exposto, vale a pena dizer que esse modo de ver o constitucionalismo contemporâneo acabou por afetar o modelo de justiça constitucional, que hoje é transnacional. Eduardo Andrés Velandia Canosa e Diana Johanna Beltrán Grande (2012, p. 102), com peculiaridade ímpar, abordaram tal modelo expressamente mencionado que o direito processual constitucional transnacional é um dos setores da teoria constitucional do processo, onde, inclusive, está localizado o direito constitucional processual e o direito processual constitucional. Os citados autores definem o direito processual constitucional transnacional da seguinte forma:

[...] es aquella rama del derecho público, que estudia el ejercicio de la justicia constitucional transnacional: i) la norma procesal constitucional transnacional; ii) el derecho de acceder al SIDH; iii) la jurisdicción constitucional transnacional; iv) el proceso constitucional transnacional; $y, v)$ el control de convencionalidad.(CANOSA e GRANDE, 2015, p. 105).

A definição traçada pelos autores colombianos revela uma importante faceta do constitucionalismo multinível porque os mesmo se preocupam em demonstrar no texto já citado, que há um direito processual transnacional mundial. 
Os aspectos destacados neste tópico revelam um novo constitucionalismo, desapegado da tradição cartesiana, em outras palavras, trata-se de um fenômeno multifacetário, de abrangência ampla e com uma vocação para atender aos interesses pluriuniversais.

Como se disse alhures, da mesma forma que o Direito Constitucional, o Direito Processual Civil sofreu grande influência da nova cosmovisão, fundada nos ideais sistêmicos e pluralistas. Ainda, pode-se afirmar que tal ramo do direito público vem há algum tempo sendo redimensionado por conta dos ditames do constitucionalismo multinível.

Isso porque não é demais lembrar que o Processo Civil, como instrumento colocado a serviço dos cidadãos da maioria dos países, tem como objetivo: a) favorecer a solução de conflitos intersubjetivos e metaindividuais, tanto na forma preventiva quanto na repressiva e b) servir de elemento basilar para qualquer Estado Democrático de Direito.

Tais ideias se revelam nos textos constitucionais de diversos países na qualidade de direito de ação ou na modalidade de direito de petição, e é sempre colocado entre os direitos fundamentais ${ }^{1}$.

O acesso do cidadão aos juízes e tribunais é permitido graças ao processo, tanto de modo formal quanto de forma concreta. Isso porque, tal instrumento, que deve tramitar sob o pálio de consagradas garantias constitucionais, resumidas na fórmula do devido processo legal, servirá para proporcionar tutela jurisdicional plena, ou seja, os órgãos jurisdicionais devem, na medida do possível, conferir aos cidadãos, que o provocam, muito mais do que uma simples decisão judicial, precisamente um resultado mais próximo da realidade, tal como se o direito não tivesse sido ameaçado ou lesado e de forma concreta e eficaz. Eis a lição de Giuseppe Chiovenda(1969, p. 46) neste sentido: "[...] o processo deve dar, quanto fôr possível pràticamente, a quem tenha um direito, tudo aquilo e exatamente aquilo que êle tenha direito de conseguir.".

Pode-se dizer, então, que um Estado Democrático de Direito forte é aquele que, diuturnamente, se preocupa em fortalecer, não só suas principais instituições e os mecanismos de participação popular, e o processo é um desses mecanismos, ainda que concebido em sentido amplo.

O processo civil tem sido utilizado para fazer valer políticas públicas, que, normalmente, deveriam ser implementadas e concretizadas pela função estatal executiva.

\footnotetext{
${ }^{1}$ Constituição da República Italiana, Art. 24. Tutti possono agire in giudizio per la tutela dei propri diritti e interessi legittimi. Constituição Espanhola, Artículo 24 1. Todas las personas tienen derecho a obtener la tutela efectiva de los Jueces y Tribunales en el ejercicio de sus derechos e intereses legítimos, sin que, en ningún caso, pueda producirse indefensión. Constituição da República Portuguesa, Art. 20, 1. A todos é assegurado o acesso ao direito e aos tribunais para defesa dos seus direitos e interesses legalmente protegidos, não podendo a justiça ser denegada por insuficiência de meios económicos.
} 
No seu âmbito também é possível verificar o debate sobre direitos fundamentais dos cidadãos de um modo geral, e de forma específica, são travadas sérias e importantes discussões em torno: I) dos direitos dos consumidores, II) dos direitos relacionados à preservação do meio ambiente para a geração presente e para as gerações futuras, III) dos direitos das minorias, IV) das pretensões e interesses jurídicos das novas modalidades de famílias, V) dos direitos oriundos da tecnologia, $\mathrm{VI}$ ) dos interesses jurídicos relacionados à biotecnologia, entre tantos outros interesses da mesma envergadura.

É importante que se diga que o alavancamento do processo civil brasileiro em especial, como indispensável instrumento de realização de direitos subjetivos, não foi fruto somente de mudanças ocorridas na legislação processual codificada ou extravagante.

Na verdade, foi com a Constituição Federal de 1988 que isso ocorreu, porque além da carta constitucional ter restaurado a democracia e os direitos fundamentais no Brasil, acabou, também, por estabelecer um modelo constitucional de processo civil, tal como escreve Cassio Scarpinella Bueno (2013, p. 111-112):

Para tratar de "direito processual civil" é insuficiente referir-se ao "Código de Processo Civil". Se é que isto já foi válido alguma vez em tempos idos, o que é certo, absolutamente certo, é que o "direito processual civil" como, de resto, todos os outros ramos e disciplinas jurídicas está inserido num contexto bem mais amplo, que é o da Constituição Federal. Não há como, para ir direto ao ponto, tratar de "direito", de "qualquer direito", sem que se volte os olhos em primeiro lugar para a Constituição. Até porque, e isto é uma especial verdade para o direito positivo brasileiro, uma mera leitura que se faça de um índice da nossa Constituição revelará que ela regula uma gama absolutamente fantástica de assuntos, quase tudo, a bem da verdade. Evitando desvios de toda a ordem, o que revela afirmar e fixar como premissa metodológica fundamental para se tratar de qualquer assunto de direito processual civil é que os dispositivos do Código de Processo Civil ou da legislação processual civil extravagante como um todo não bastam por si sós. Não estão "soltos". Mais ainda: é insuficiente para a tão conhecida e festejada "interpretação sistemática do direito" compararem-se alguns poucos textos de lei com outros textos da mesma ou de outra lei para estabelecer, entre eles, uma aparente ordem de "regra geral" para "regra específica" ou de "regra geral" para "regra excepcional". Mais importante do que tudo isto e que deve ser postos em primeiro lugar, inclusive em ordem de pensamento, é verificar em que medida a Constituição Federal quer que o direito processual civil seja. É verificar, na Constituição Federal, qual é (ou, mais propriamente, qual deve ser) o "modo de ser" (de dever ser) do direito processual civil como um todo. É extrair, da Constituição Federal, o "modelo constitucional do direito processual civil" e, a partir dele, verificar em que medida as disposições legais anteriores à sua entrada em vigência foram por ela recepcionadas e em que medida as disposições normativas baixadas desde então se encontram em plena consonância com aqueles valores ou, escrito de forma mais precisa, bem 
realizam os desideratos que a Constituição impõe sejam realizados pelo direito processual civil ou que têm condições de concretizar o modelo constitucional do direito processual civil.

É aqui que justamente se percebe a influência do constitucionalismo contemporâneo. Isso porque a tutela jurisdicional plena, buscada por meio do processo civil, somente se concretiza quando o jurisdicionado tem: I) efetivo acesso ao Judiciário; II) acesso à uma decisão judicial que possa restabelecer o máximo possível o status quo ante, quando se trata de contencioso repressivo ou acesso a uma decisão judicial que o proteja, nos casos de contencioso preventivo e inibitório e, principalmente; III) a uma efetiva realização no mundo fático do direito declarado, em sentido amplo, ou protegido pelas decisões judiciais.

Todos esses desideratos demonstram que o Direito Processual Civil não é um fim em si mesmo, ao contrário, ele é multinível também, porque existe para fazer valer direitos fundamentais.

Essa visão pluriuniversal do direito processual civil atual, conforme as exigências da sociedade, que almeja a paz e o bem comum, podem ser resumido nos seguintes pontos: a) 0 processo é um instrumento pelo qual serão atingidos escopos sociais, políticos, econômicos, jurídicos e pedagógicos; b) O processo, em que pese sua autonomia científica, está intimamente relacionado com o direito material, porque este último deve ser o motivo maior de toda atividade processual e por conta da influência que tal ramo exerce na maioria dos institutos processuais; c) O processo é um instrumento ético e não simplesmente técnico; d) O processo deve ser descomplicado (simplex) e moderno, de modo que tais qualificativos se tornem também norteadores da interpretação e aplicação da lei processual e e)O processo deve ser guiado por um modelo ou padrão constitucional, representado por corolários do devido processo legal.

O último aspecto desse quadro merece destaque, pois relacionado à "constitucionalização do processo"; fenômeno mundial consagrado e sobre o qual não pairam mais dúvidas, tanto em sede doutrinária quanto jurisprudencial.

Essa influência multifacetária do constitucionalismo está presente no novo Código de Processo Civil brasileiro, é o que verifica do teor da Lei Federal 13.105/ 2015. De forma expressa, se pode verificar tal fator no fato do legislador ter adotado um capítulo sobre as normas fundamentais processuais, algumas delas oriundas do texto constitucional - é o que se pode conferir do Capítulo I, do Título Único, do Livro I da Parte Geral, especialmente os Arts. 1ㅇa 11.

A título de exemplo, vale destacar a adoção do princípio da cooperação processual, o qual passa acaba por introduzir no sistema processual uma nova forma de processo, qual seja o 
cooperativo, ao lado do dispositivo e do inquisitivo. Neste sentido, destaque-se a lição de Fredie Didier Júnior (2015, p. 125):

A condução do processo deixa de ser determinada pela vontade das partes (marca do processo liberal dispositivo). Também não se pode afirmar que há uma condução inquisitorial do processo pelo órgão jurisdicional, em posição assimétrica em relação às partes. Busca-se uma condução cooperativa do processo, sem destaques para qualquer dos sujeitos processuais.

Merecedor de destaque, também, é a importância dada ao contraditório, que deverá sempre ser observado, ainda que o juiz possa julgar a matéria de ofício, nos termos do Art. 70 do novo CPC. E neste mesmo sentido, com a valorização de uma atuação dialógica, o legislador adotou a proibição das decisões-surpresa, tal como se vê do teor do Art. 10 do NCPC ${ }^{2}$. Sobre tal dispositivo, eis a lição de Zulmar Duarte de Oliveira Júnior (2015, p. 65):

[...] sempre que o campo de visão do juiz alcançar questão não constante daquele compartilhado pelas partes no processo, deverá dar a oportunidade para elas se manifestarem previamente sobre o tema. A necessidade de compartilhamento ds respectivas visões do processo evita potenciais danos às partes, por eventual miopia ou cegueira no tema do juiz, e também decorre dos deveres de consulta e auxílio próprios da cooperação processual (artigo 6 ).

Tudo isso revela, notoriamente, que o Processo Civil transformou-se em instrumento fundamental para o Estado Democrático de Direito, especialmente em países como o Brasil, que viveram recentes períodos antidemocráticos, nos quais os cidadãos se viram, muitas vezes, privados do acesso à justiça.

\section{CONCLUSÃO}

A cosmovisão tem sofrido mudanças estruturais importantes para o estabelecimento de novos paradigmas envolvendo as ciências sociais, entre elas o Direito.

O modo sistemático e pluriuniversal gerou a modificação do Direito Constitucional, que deixou de ser estritamente legalista e passou a ser visto como um fenômeno multinível. Essa mesma visão renovada acabou por alterar os ditames do Direito Processual Civil, pois guiado pelos interesses fundamentais de todos os cidadãos e para a concretização dos direitos violados ou para a preservação de direitos ameaçados, iluminados pelo modelo constitucional de processo, o qual agora é adotado de forma expressa pela Lei Federal 13.105/2015, geradora do Novo Código de Processo Civil.

\footnotetext{
${ }^{2}$ Art. 10.0 juiz não pode decidir, em grau algum de jurisdição, com base em fundamento a respeito do qual não se tenha dado às partes oportunidade de se manifestar, ainda que se trate de matéria sobre a qual deva decidir de ofício. 


\section{REFERÊNCIAS}

BUENO, Cassio Scarpinella. Curso sistematizado de direito processual civil. 7ạ ed. São Paulo : Saraiva, 2013, p. 111-112. Vol.1

CANOSA, Eduardo Andrés Velandia e GRANDE, Diana Johanna Beltrán. La justicia constitucional y su modelo transnacional. In: CANOSA, Eduardo Andrés Velandia. Derecho procesal constitucional. Bogotá : VC Editores, 2012. p. 102. Tomo III, vol I.

CAPRA, Fritjof. As conexões ocultas: ciência para uma vida sustentável. Tradução de Marcelo Brandão Cipolla. São Paulo : Ed. Cultrix, 2002. p. 27.

CHIOVENDA, Giuseppe. Instituições de direito processual civil. Tradução de J. Guimarães Menegale. 3a ed. São Paulo : Saraiva, 1969, p. 46).

DIDIER JÚNIOR, Fredie. Curso de direito processual civil. 17ạ ed. Salvador : JusPodivm, 2015, vol. 1.

GAJARDONI, Fernando da Fonseca. DELLORE, Luiz. ROQUE, André Vasconcelos e OLIVEIRA JÚNIOR, Zulmar Duarte de. Teoria geral do processo. Comentários do CPC de 2015. Parte Geral. São Paulo : Método, 2015.

MORA, José Ferrater. Ensaio introdutório às etapas da filosofia de Ortega y Gasset. In: ORTEGA y GASSET, José. Origem e epílogo da filosofia. Rio de Janeiro : Livro Ibero-Americano, 1963. p. 44.

MÜLLER, Friedrich. Metodologia do direito constitucional. 4a ed. São Paulo : RT, 2010. p. 27.

ORTEGA y GASSET, José. História como sistema. Tradução de Juan A. Gili Sobrinho e Elizabeth Hanna Côrtes Costa. Brasília : UnB, 1982. p. 28).

SILVA, Caíque Tomaz Leite da. A tutela interconstitucional do processo. Revista dos Tribunais. São Paulo : RT, no 941, p. 131, mar. 2014. 